\title{
Prevalence and factors associated with exclusive breastfeeding at 6 months of life in Tehran: a population-based study
}

\author{
Z.S. Noughabi, ${ }^{1}$ S. Golian Tehrani, ${ }^{1}$ A.R. Foroushani, ${ }^{2}$ F. Nayeri ${ }^{3}$ and A. Baheiraei ${ }^{4}$
}

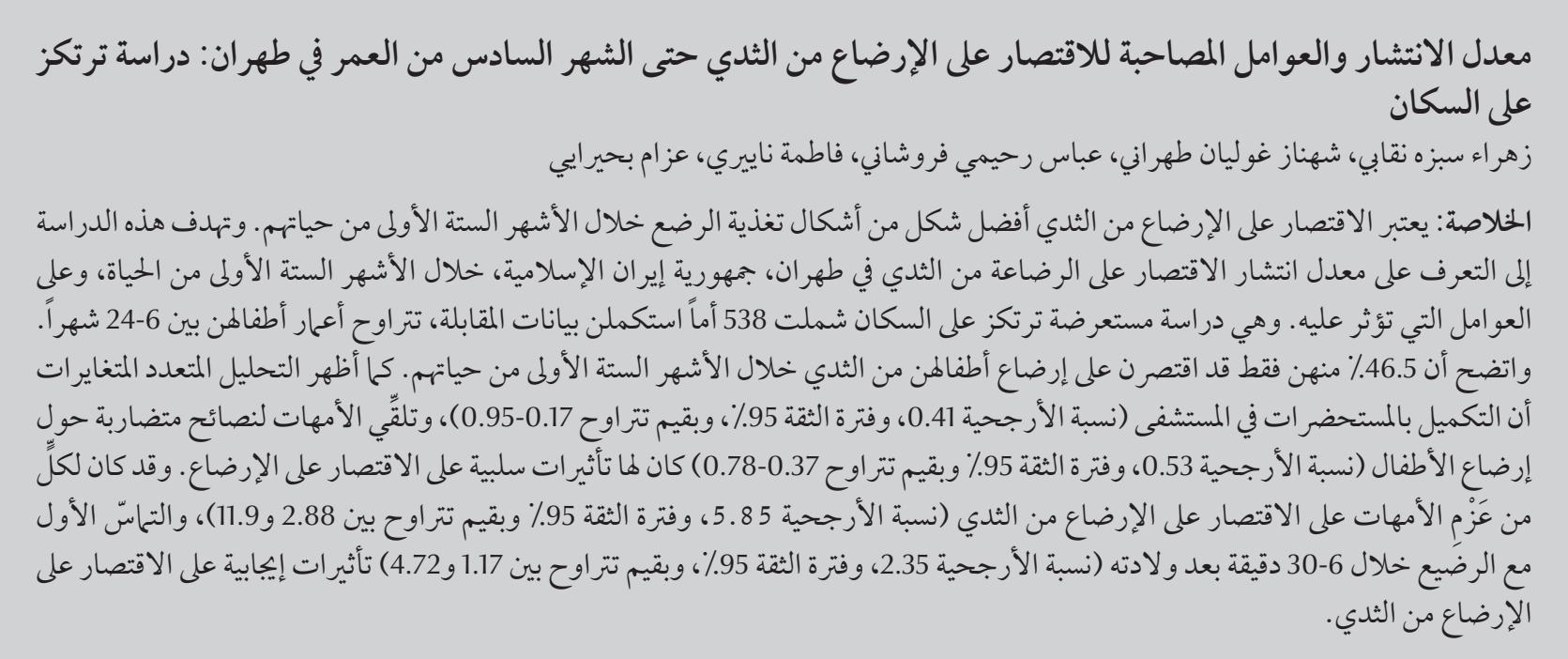

ABSTRACT Exclusive breastfeeding is the best form of nutrition for infants in the first 6 months of life. The aim of this study was to determine the prevalence of exclusive breastfeeding in Tehran, Islamic Republic of Iran in the first 6 months of life, and the factors that influence it. In a population-based, cross-sectional study 538 mothers with children aged 6-24 months completed an interview questionnaire. Only 46.5\% of mothers exclusively breastfed their infant in the first 6 months of life. In multivariate analysis formula supplementation in the hospital $(\mathrm{OR}=0.41,95 \% \mathrm{Cl}: 0.17-0.95)$ and mother receiving conflicting infant feeding advice $(\mathrm{OR}=0.53,95 \% \mathrm{Cl}$ : $0.37-$ $0.78)$ had a negative effect on exclusive breastfeeding. Mother's intention to exclusively breastfeed $(\mathrm{OR}=5.85$, 95\% Cl: 2.88-11.9) and infant having first breast contact 6-30 minutes after delivery (OR = 2.35, 95\% Cl: 1.17-4.72) had positive effects on exclusive breastfeeding.

Prévalence et facteurs associés à l'allaitement maternel exclusif à six mois de vie à Téhéran : une étude en population générale

RÉSUMÉ L'allaitement maternel exclusif est la meilleure forme d'alimentation pour les nourrissons dans les six premiers mois de vie. La présente étude visait à déterminer la prévalence de l'allaitement maternel exclusif à Téhéran (République islamique d'Iran) dans les six premiers mois de vie et ses facteurs d'influence. Au cours d'une étude transversale en population, 538 mères d'enfants âgés de 6 à 24 mois ont rempli un questionnaire en entretien. Seules 46,5\% des mères avaient allaité exclusivement leur nourrisson dans les six premiers mois de vie. D'après une analyse multivariée, le lait en poudre à l'hôpital (O.R. = 0,41; IC à $95 \%$ : 0,17-0,95) et des conseils d'alimentation contradictoires prodigués à la mère (O.R. = 0,53; IC à 95\%:0,37-0,78) avaient des effets négatifs sur l'allaitement maternel exclusif. En revanche, I'intention de la mère d'allaiter exclusivement $(O . R .=5,85$; IC à $95 \%: 2,88-11,9)$ et une première mise au sein entre 6 et 30 minutes après l'accouchement (O.R. = 2,35; IC à $95 \%$ : 1,17-4,72) avaient des effets positifs sur l'allaitement maternel exclusif. 


\section{Introduction}

Exclusive breastfeeding is the best form of nutrition for infants in the first 6 months of life as breast milk protects the child against respiratory infections, diarrhoea, asthma and allergy [1]. It also appears to decrease the risk of sudden infant death syndrome, atopic diseases, lymphoma, mortality and morbidity from infectious diseases $[2,3]$. Several studies have shown the effect of breastfeeding on protection against obesity, type 2 diabetes, acute leukaemia and colic [1-3]. Exclusive breastfeeding in the first 6 months of life has other advantages such as helping mothers bond with their infants, playing an important role in the health of the mother by decreasing postpartum haemorrhage and the risk of premenopausal breast cancer, ovarian cancer and osteoporosis; lactating woman have an earlier return to pre-pregnant weight [1]. In addition, exclusive breastfeeding provides significant social and economic benefits to the nation including reduced health-care costs and reduced employee absenteeism for care attributable to child illness [3].

In the Islamic Republic of Iran, the percentage of infants exclusively breastfed in the first 6 months of life has been reported as anywhere between $13 \%$ and $77 \%$ in different studies in various parts of the country [4-8]. Numerous factors have been associated with exclusive breastfeeding, and being aware of these influences can inform interventions on encouraging exclusive breastfeeding, which is of vital importance for mothers, clinicians and society in general. The decision to begin and continue exclusive breastfeeding can be influenced by factors such as maternal age and self-confidence, infant diseases, gestational age, birth weight, maternal education level, father's occupation, type of delivery, whether the infant is meeting growth milestones or not and the mother's awareness of the sufficiency of her breast milk [4-8].
To the best of our knowledge, no previous studies have been conducted in Tehran about the determinants of exclusive breastfeeding. The aim of this population-based study was to determine the prevalence of exclusive breastfeeding in the first 6 months of life and the influencing factors (sociodemographic, childbirth and postpartum) with a focus on postpartum factors.

\section{Methods}

\section{Study design and sample}

This was a cross-sectional study conducted in Tehran, the capital city of Islamic Republic of Iran. In a previous study, the prevalence of exclusive breastfeeding for infants at 6 months of age in Tehran was found to be $35 \%$ [4]. The sample size was determined assuming $95 \%$ confidence interval (CI) and $80 \%$ power of test. Based on this, 547 mothers were interviewed and the data from 538 mothers were analysed (98.4\% response rate).

The subjects were mothers with infants aged 6-24 months living in Tehran. Sampling began in the most densely populated part of each of the 22 districts in Tehran according to the population map of Tehran. We visited every house in the area, and women meeting the criteria for our study and willing to participate were recruited using a multistage, random cluster technique. Data gathering was conducted in June and July 2011. The questionnaire was completed by a face-to-face interview. The inclusion criteria were having an infant aged 6-24 months, a singleton baby, living in Tehran during the previous year and Iranian nationality.

Participation in the study was voluntary and written consent was obtained from all the mothers prior to their participation. Tehran University of Medical Sciences granted ethical approval for the study.

\section{Data collection}

In this study, the variables collected were: parental sociodemographic factors (mother's age, education level, ethnicity, employment, work status before delivery, marital status, parity and use of cigarettes; father's age, education level, employment and ethnicity; household income and area of residence); childbirth factors (mode of delivery, infant's sex, birth weight, gestational age and birth health); and postpartum factors (infant admitted to the neonatal care unit, when infant was put to the breast, skin-to-skin contact, infant being demand fed, mother's intention to breastfeed before childbirth, health problems within 6 months of delivery, clinician assistance with breastfeeding, clinician counselling on exclusive breastfeeding, formula supplementation at hospital after birth, husband's support for exclusive breastfeeding, family and friends' support for exclusive breastfeeding, mother receiving conflicting infant feeding advice, pacifier use during the first week of life, mother having enough time for exclusive breastfeeding, mother's breastfeeding history and postnatal depression)

All information was gathered via a questionnaire and interview with the mother. Exclusive breastfeeding was defined according to the World Health Organization definition [2]. The information regarding postnatal depression was obtained using the Edinburgh Depression Scale. This scale has 10 items scored from $0-3$ and the mother was asked to base her answers on the previous 7 days. A total score of $\geq 12$ indicated postnatal depression. Since depression symptoms may exist for up to 24 months postpartum, the mothers were classified into 2 groups: depressed and non-depressed.

\section{Data analysis}

The dependent variable in this study was exclusive breastfeeding in the first 6 months of life. Independent variables 
associated with exclusive breastfeeding were compared separately using a chi-squared test. If these variables were significant, they were entered into a multivariable logistic regression analysis. $P$-values $<0.05$ were considered as statistically significant and the data were analysed by SPSS, version 18.0.

\section{Results}

\section{Background variables}

The mean age of participating children was 13.8 (SD 5.4) months; $50.9 \%$ were girls and $49.1 \%$ were boys. The mean birth weight of the study children was 3485 (SD 424) g; 90.3\% of infants had a normal birth weight (2500-4000 g). Of the infants $74.7 \%$ were born at term (37 weeks gestation or more). More than half of infants (60.2\%) were born by caesarean section and 39.8\% were born via normal vaginal delivery. Although 47 infants (8.7\%) had health problems at birth, $91.3 \%$ of infants were born healthy.

Around one-quarter of mothers $(131,24.3 \%)$ reported that their household income was insufficient to meet the needs of the family. In addition, $67.5 \%$ of mothers were aged $25-30$ years. Only 75 mothers (13.9\%) were working before the birth of their child. More than half of the parents had diploma level education or above. Nearly all mothers (99.8\%) were married and only 1 was divorced; thus we did not analyse marital status as a factor. No mothers smoked during pregnancy, although 4 mothers $(0.7 \%)$ smoked during breastfeeding. Due to the small number of cigarette-smoking mothers, we did not analyse this factor. Postnatal depression was diagnosed in 102 mothers (19.0\%) according to the Edinburgh Depression Scale.

\section{Prevalence of exclusive breastfeeding}

The prevalence of exclusive breastfeeding of infants at birth, as reported by the mothers, was $95.0 \%$. Of the mothers $43.5 \%$ put the child to the breast in the first half hour of life, but 5 mothers had never put their infant to their breast. During the first week after birth, 361 mothers breastfed on demand, 105 breastfed according to a fixed programme and the others fed with a combination of these methods. Seventy-three mothers used a pacifier during the infant's first week of life.

Figure 1 shows that the reported prevalence of exclusive breastfeeding declined steadily over the 6 months after birth. At 6 months only $46.5 \%$ of mothers were exclusively breastfeeding their infants. A few mothers (4.6\%) used formula milk and $25.5 \%$ used something other than formula (e.g. mixing rice with milk and sugar, tea, sweetened water and juice) (Table 1). The mean duration of exclusive breastfeeding was 4.4 (SD 1.9) months. Only $7.4 \%$ of mothers were still breastfeeding their infant at 23-24 months.

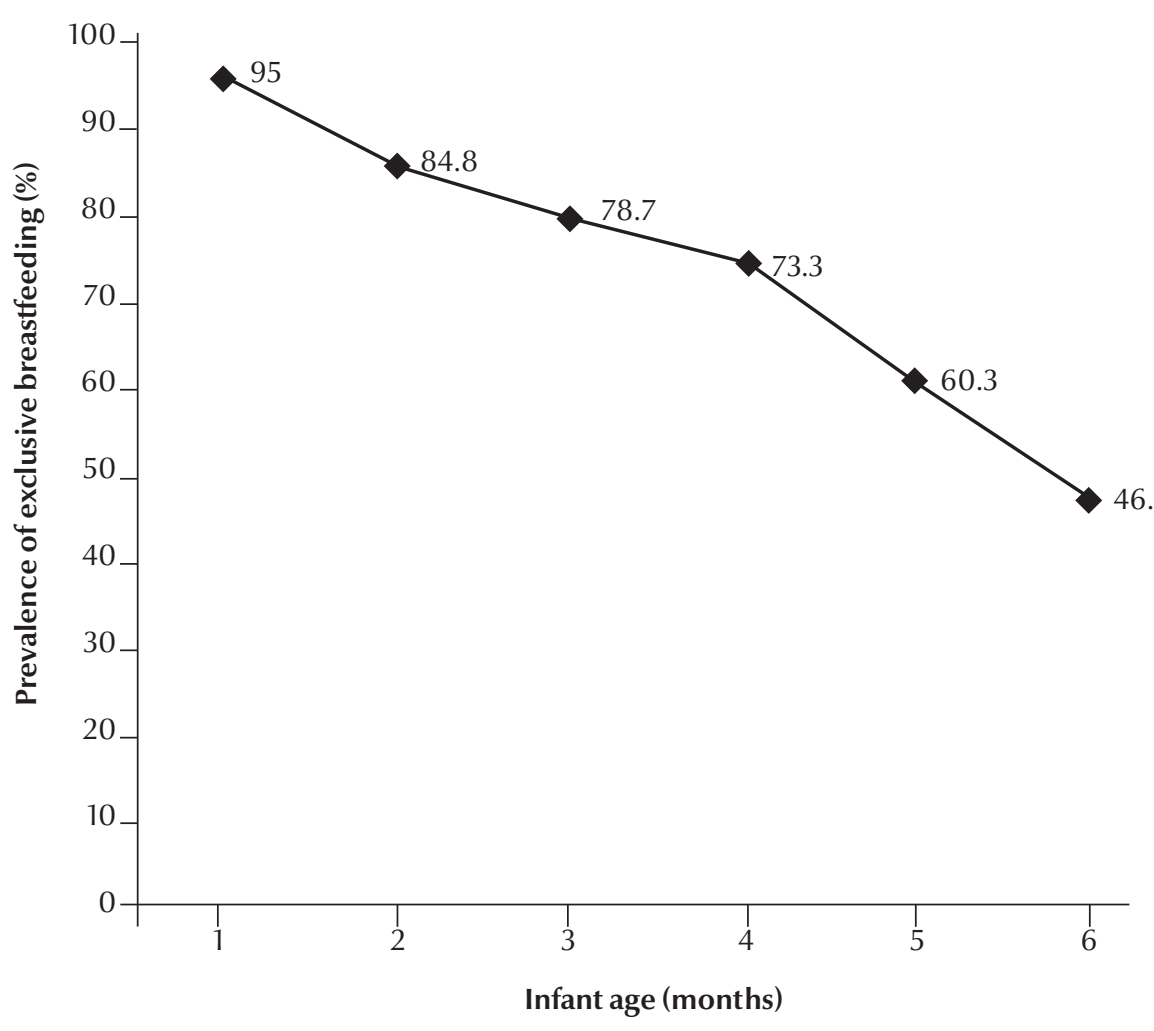

Figure 1 Rates of exclusive breastfeeding during the first 6 months of infant's life ( $n=538$ mothers)
When asked about their intentions before the birth $86.4 \%$ of mothers said they had intended to breastfeed exclusively and $4.1 \%$ had intended to use formula prior to childbirth. Of the mothers $83.6 \%$ had the support of their husband and relatives with regard to exclusive breastfeeding and $60 \%$ did not have any breastfeeding history.

\section{Bivariate analysis}

Using a chi-squared test with $95 \% \mathrm{CI}$, no relationship was found between exclusive breastfeeding and sociodemographic factors or childbirth factors (Tables 2 and 3). Some postpartum factors were significantly associated with exclusive breastfeeding including the time of first skin-to-skin contact $(P$ $=0.014)$, the time of the first breastfeed $(P=0.005)$, mother's intention to breastfeed before childbirth $(P<0.001)$, formula supplementation in hospital after birth $(P=0.046)$, husband's support for exclusive breastfeeding $(P=0.021)$, 


\begin{tabular}{lcc}
\hline Table 1 Frequency of feeding methods in the first $\mathbf{6}$ months of infant's life \\
Feeding & No. of mothers & $\%$ \\
Formula & 25 & 4.6 \\
Exclusive breastfeeding & 250 & 46.5 \\
Combination of formula and & 126 & 23.4 \\
breastfeeding & 137 & 25.5 \\
Other & 538 & 100.0 \\
Total
\end{tabular}

having enough time for exclusive breastfeeding $(P=0.001)$, mother receiving conflicting infant feeding advice in the first 6 months $(P<0.001)$, family support for exclusive breastfeeding $(P=$ $0.016)$ and pacifier use during the first week of life $(P=0.035)$. These variables were included in the final model.

\section{Multivariable logistic regression analysis}

In the multivariable logistic regression analysis, the following factors were left in the model: mother's intention to breastfeed before childbirth, timing of the first breastfeeding, mother receiving conflicting infant feeding advice and formula supplementation at hospital after birth.

When the first breastfeeding was 6-30 minutes after childbirth, it had a positive effect on exclusive breastfeeding in the first 6 months of life (OR $=2.35$, 95\% CI: 1.17-4.72) (Table 4). A delay in the first breastfeeding decreased the chances of successful exclusive breastfeeding in the first 6 months. Mothers who intended to exclusively breastfeed before childbirth were 6 times more likely to exclusively breastfeed than mothers who did not intend to exclusively breastfeed before childbirth $(\mathrm{OR}=5.85,95 \% \mathrm{CI}$ : 2.88-11.9).

Formula supplementation in the hospital and mothers receiving conflicting infant feeding advice had a negative effect on the duration of exclusive breastfeeding in the first 6 months of life ( $\mathrm{OR}=0.41,95 \%$ CI: $0.17-0.95$ and $\mathrm{OR}$ $=0.53,95 \%$ CI: $0.37-0.78$ respectively).

\section{Discussion}

Exclusive breastfeeding in the first 6 months of life has been shown to be one of the main factors that can reduce infant mortality [2]. In our study, the prevalence of exclusive breastfeeding in Tehran clearly decreased, from $95.0 \%$ at birth to $46.5 \%$ at age 6 months. This rate of exclusive breastfeeding at the 6-month mark was higher than that found in previous studies in some other cities in the Islamic Republic of Iran, such as Yazd and Kashan, but lower than in Mashhad [4-8]. Due to the lack of data in Tehran, a comparison was not possible. In studies conducted in other countries, the number of infants who were exclusively breastfed at 6 months of age ranged from $1 \%-43 \%$; thus our study has shown that the prevalence of exclusive breastfeeding in Tehran was higher than some countries [9-12]. It is obvious that differences in culture, study design and study population and number of subjects in these studies may have contributed to these differences.

Ourstudy found that if the first infant breastfeeding occurred during the 6-30 minutes after childbirth this had a positive effect on exclusive breastfeeding at 6 months of life (OR $=2.35,95 \% \mathrm{CI}$ : 1.17-4.72). This result is in line with the findings of Eslami et al. [8] and RoweMurray and Fisher [13] but disagrees with Nakao et al. [14]. Early breastfeeding is one of the factors contributing to the success of exclusive breastfeeding $[1,15]$. The timing of first breastfeeding is crucial and when it occurs before the first 30 minutes after childbirth, the chances of a mother being able to exclusively breastfeed for the first 6 months of her infant's life are improved [13]. The aim of beginning breastfeeding may be different. The aim is sometimes to have a successful and complete breastfeeding or sometimes, like the present study, only a short breastfeeding. Therefore, this difference may be due to differences in classifying the time of breastfeeding in the data analysis.

In this study, mothers who received conflicting infant feeding advice in their infant's first 6 months of life were less likely to exclusively breastfeed for up to 6 months ( $\mathrm{OR}=0.53,95 \%$ CI: 0.37 0.78 ). In other studies $[16,17]$, mothers who were supported after childbirth had their first breastfeed earlier than mothers who were not supported, and were more likely to exclusively breastfeed when the husband and family supported exclusive breastfeeding $[17,18]$. On the other hand, many behaviours are influenced by social customs, which are influenced by a person's beliefs and often the wishes of other family members. In the Islamic Republic of Iran and some Asian countries, a woman's family members and husband may strongly influence a mother's decisions.

Mothers who received formula supplementation in hospital after childbirth were less likely to exclusively breastfeed their infant in the first 6 months of life $(\mathrm{OR}=0.41,95 \%$ CI: $0.17-0.95)$. This is consistent with some previous studies $[19,20]$. The reason for mothers failing to exclusively breastfeed in their infant's first 6 months of life can be a lack of support for exclusive breastfeeding [20] and receiving formula supplementation at hospital or receiving other support on formula that led to lack of self-confidence about exclusive breastfeeding.

In this study, we found that a mother's intention to breastfeed before childbirth was associated with exclusive breastfeeding in the first 6 months of life $(\mathrm{OR}=5.85,95 \% \mathrm{CI}: 2.88-11.9)$ and this finding confirms the findings of other studies [20-22]. Mothers 


\begin{tabular}{|c|c|c|c|c|c|}
\hline \multirow[t]{3}{*}{ Variable } & \multirow{3}{*}{$\begin{array}{c}\text { No. of } \\
\text { mothers }\end{array}$} & \multicolumn{2}{|c|}{ Exclusive breastfeeding } & \multirow[t]{3}{*}{$x^{2}(\mathrm{df})$} & \multirow[t]{3}{*}{$P$-value } \\
\hline & & Yes & No & & \\
\hline & & $\%$ & $\%$ & & \\
\hline \multicolumn{6}{|c|}{ Maternal variables } \\
\hline Mother's age (years) & & & & $0.149(2)$ & 0.928 \\
\hline$\leq 25$ & 155 & 47.7 & 52.3 & & \\
\hline $26-30$ & 208 & 46.2 & 53.8 & & \\
\hline$\geq 30$ & 175 & 45.7 & 54.3 & & \\
\hline Mother's education level & & & & $5.108(3)$ & 0.164 \\
\hline Illiterate/elementary & 41 & 39.0 & 61.0 & & \\
\hline Secondary/high school & 96 & 53.1 & 46.9 & & \\
\hline High school diploma & 260 & 48.5 & 51.5 & & \\
\hline University & 141 & 40.4 & 59.6 & & \\
\hline Mother's employment & & & & $0.924(1)$ & 0.336 \\
\hline Employed & 75 & 41.3 & 58.7 & & \\
\hline Unemployed & 463 & 47.3 & 52.7 & & \\
\hline Mother's ethnicity & & & & $0.785(2)$ & 0.675 \\
\hline Persian & 297 & 45.5 & 54.5 & & \\
\hline Azari & 144 & 45.8 & 54.2 & & \\
\hline Other & 97 & 50.5 & 49.5 & & \\
\hline Mother's return to work after delivery (months) ${ }^{a}$ & & & & $2.723(1)$ & 0.256 \\
\hline$<6$ & 23 & 47.8 & 52.2 & & \\
\hline$\leq 6$ & 52 & 38.4 & 61.6 & & \\
\hline Parity & & & & $1.174(2)$ & 0.556 \\
\hline 1 & 299 & 44.5 & 53.5 & & \\
\hline 2 & 190 & 48.3 & 51.7 & & \\
\hline$\geq 3$ & 49 & 51.0 & 49.0 & & \\
\hline \multicolumn{6}{|c|}{ Paternal variables } \\
\hline Father's age (years) & & & & $1.004(2)$ & 0.605 \\
\hline$\geq 29$ & 121 & 43.8 & 56.2 & & \\
\hline $30-35$ & 245 & 45.7 & 54.3 & & \\
\hline$\geq 36$ & 172 & 49.4 & 50.6 & & \\
\hline Father's education level & & & & $5.858(3)$ & 0.119 \\
\hline Illiterate/ elementary & 50 & 48.0 & 52.0 & & \\
\hline Secondary/ high school & 104 & 56.7 & 43.3 & & \\
\hline High school diploma & 237 & 43.9 & 56.1 & & \\
\hline University & 147 & 42.9 & 57.1 & & \\
\hline Father's employment & & & & $0.722(2)$ & 0.697 \\
\hline Unemployed & 19 & 42.1 & 57.9 & & \\
\hline Government & 176 & 44.3 & 55.7 & & \\
\hline Non-government & 343 & 47.8 & 52.2 & & \\
\hline Father's ethnicity & & & & $2.745(2)$ & 0.253 \\
\hline Persian & 285 & 48.8 & 51.2 & & \\
\hline Azari & 143 & 40.6 & 59.4 & & \\
\hline Other & 110 & 48.2 & 51.8 & & \\
\hline
\end{tabular}




\begin{tabular}{|c|c|c|c|c|c|}
\hline \multirow[t]{3}{*}{ Variable } & \multirow[t]{3}{*}{ No. of mothers } & \multicolumn{2}{|c|}{ Exclusive breastfeeding } & \multirow[t]{3}{*}{$\chi^{2}(\mathrm{df})$} & \multirow[t]{3}{*}{$P$-value } \\
\hline & & Yes & No & & \\
\hline & & $\%$ & $\%$ & & \\
\hline \multicolumn{6}{|c|}{ Household variables } \\
\hline Household income & & & & $0.186(2)$ & 0.911 \\
\hline Sufficient & 131 & 48.1 & 51.9 & & \\
\hline Relatively sufficient & 353 & 45.9 & 54.1 & & \\
\hline Insufficient & 54 & 46.3 & 53.7 & & \\
\hline Area of residence & & & & $8.691(4)$ & 0.069 \\
\hline North & 51 & 43.1 & 56.9 & & \\
\hline South & 162 & 49.1 & 50.9 & & \\
\hline East & 163 & 52.4 & 47.6 & & \\
\hline West & 113 & 42.5 & 57.5 & & \\
\hline City centre & 49 & 30.6 & 69.4 & & \\
\hline
\end{tabular}

${ }^{a} n=75$.

$d f=$ degrees of freedom.

\begin{tabular}{|c|c|c|c|c|c|}
\hline \multirow[t]{3}{*}{ Variable } & \multirow[t]{3}{*}{ No. of mothers } & \multicolumn{2}{|c|}{ Exclusive breastfeeding } & \multirow[t]{3}{*}{$\chi^{2}(\mathrm{df})$} & \multirow[t]{3}{*}{$P$-value } \\
\hline & & Yes & No & & \\
\hline & & $\%$ & $\%$ & & \\
\hline \multicolumn{6}{|c|}{ Childbirth variables } \\
\hline Mode of delivery & & & & $0.204(1)$ & 0.651 \\
\hline Vaginal & 214 & 47.7 & 52.3 & & \\
\hline Caesarean & 324 & 45.7 & 54.3 & & \\
\hline Infant's sex & & & & $0.559(1)$ & 0.254 \\
\hline Male & 264 & 48.1 & 51.9 & & \\
\hline Female & 274 & 44.9 & 55.1 & & \\
\hline Infant's birth weight (g) & & & & $3.269(2)$ & 0.195 \\
\hline$\leq 2500$ & 34 & 35.3 & 64.7 & & \\
\hline $2500-4000$ & 486 & 46.7 & 53.3 & & \\
\hline$\geq 4000$ & 18 & 61.1 & 38.9 & & \\
\hline Infant's birth age (week) & & & & $0.026(1)$ & 0.873 \\
\hline$<37$ & 136 & 47.1 & 52.9 & & \\
\hline$\geq 37$ & 402 & 46.3 & 53.7 & & \\
\hline Infant's birth health & & & & $2.196(1)$ & 0.091 \\
\hline Healthy & 491 & 47.5 & 52.5 & & \\
\hline Unhealthy & 47 & 36.2 & 63.8 & & \\
\hline \multicolumn{6}{|c|}{ Postpartum variables } \\
\hline $\begin{array}{l}\text { Health problem in the } 6 \text { months after } \\
\text { delivery }\end{array}$ & & & & $0.053(1)$ & 0.818 \\
\hline Yes & 177 & 45.8 & 54.2 & & \\
\hline No & 361 & 46.8 & 53.2 & & \\
\hline Postnatal depression & & & & $0.019(1)$ & 0.892 \\
\hline Yes & 83 & 45.8 & 54.2 & & \\
\hline No & 455 & 46.6 & 53.4 & & \\
\hline
\end{tabular}




\begin{tabular}{|c|c|c|c|c|c|}
\hline \multirow[t]{3}{*}{ Variable } & \multirow[t]{3}{*}{ No. of mothers } & \multicolumn{2}{|c|}{ Exclusive breastfeeding } & \multirow[t]{3}{*}{$x^{2}(\mathrm{df})$} & \multirow[t]{3}{*}{$P$-value } \\
\hline & & Yes & No & & \\
\hline & & $\%$ & $\%$ & & \\
\hline \multicolumn{6}{|c|}{ Postpartum variables } \\
\hline Infant admitted to neonatal care unit & & & & $0.008(1)$ & 0.930 \\
\hline Yes & 102 & 46.1 & 53.9 & & \\
\hline No & 436 & 46.6 & 53.4 & & \\
\hline Infant put to the breast (time after birth) & & & & $14.71(4)$ & 0.005 \\
\hline $0-5 \min$ & 115 & 57.4 & 42.6 & & \\
\hline $6-30 \mathrm{~min}$ & 119 & 52.9 & 47.1 & & \\
\hline $30 \mathrm{~min}-2 \mathrm{~h}$ & 200 & 42.0 & 58.0 & & \\
\hline $2-12 \mathrm{~h}$ & 59 & 32.2 & 67.8 & & \\
\hline$>12 \mathrm{~h}$ & 45 & 40.0 & 60.0 & & \\
\hline Skin-to-skin contact & & & & $12.56(4)$ & 0.014 \\
\hline $0-5 \min$ & 124 & 48.4 & 51.6 & & \\
\hline $6-30 \mathrm{~min}$ & 124 & 58.1 & 41.9 & & \\
\hline $30 \mathrm{~min}-2 \mathrm{~h}$ & 107 & 45.8 & 54.2 & & \\
\hline $2-6 \mathrm{~h}$ & 143 & 37.8 & 62.2 & & \\
\hline$>6 \mathrm{~h}$ & 40 & 37.5 & 62.5 & & \\
\hline Infant breastfed on demand & & & & $6.00(2)$ & 0.050 \\
\hline Yes & 361 & 44.0 & 56.0 & & \\
\hline No & 105 & 57.1 & 42.9 & & \\
\hline Occasionally & 72 & 43.1 & 56.9 & & \\
\hline $\begin{array}{l}\text { Mother's intention to breastfeed before } \\
\text { childbirth }\end{array}$ & & & & $36.46(1)$ & $<0.001$ \\
\hline Exclusive breastfeeding & 465 & 51.6 & 48.4 & & \\
\hline Non-exclusive breastfeeding & 73 & 13.7 & 86.3 & & \\
\hline Clinician help with breastfeeding & & & & $2.238(1)$ & 0.134 \\
\hline Yes & 348 & 48.9 & 51.1 & & \\
\hline No & 190 & 42.1 & 57.9 & & \\
\hline $\begin{array}{l}\text { Clinician counselling on exclusive } \\
\text { breastfeeding }\end{array}$ & & & & $0.007(1)$ & 0.936 \\
\hline Yes & 399 & 46.4 & 53.6 & & \\
\hline No & 139 & 46.8 & 53.2 & & \\
\hline $\begin{array}{l}\text { Formula supplementation in hospital after } \\
\text { birth }\end{array}$ & & & & $3.464(1)$ & 0.046 \\
\hline Yes & 30 & 30.0 & 70.0 & & \\
\hline No & 508 & 47.4 & 52.6 & & \\
\hline $\begin{array}{l}\text { Husband's support of exclusive } \\
\text { breastfeeding }\end{array}$ & & & & $5.344(1)$ & 0.021 \\
\hline Yes & 450 & 48.7 & 51.3 & & \\
\hline No & 88 & 35.2 & 64.8 & & \\
\hline $\begin{array}{l}\text { Family and friends' support of exclusive } \\
\text { breastfeeding }\end{array}$ & & & & $3.741(1)$ & 0.035 \\
\hline Yes & 468 & 48.1 & 51.9 & & \\
\hline No & 70 & 35.7 & 64.3 & & \\
\hline $\begin{array}{l}\text { Mother received conflicting infant feeding } \\
\text { advice }\end{array}$ & & & & $12.91(1)$ & $<0.001$ \\
\hline Yes & 216 & 37.0 & 63.0 & & \\
\hline No & 322 & 52.8 & 47.2 & & \\
\hline
\end{tabular}




\begin{tabular}{|c|c|c|c|c|c|}
\hline \multirow[t]{3}{*}{ Variable } & \multirow[t]{3}{*}{ No. of mothers } & \multicolumn{2}{|c|}{ Exclusive breastfeeding } & \multirow[t]{3}{*}{$x^{2}(\mathrm{df})$} & \multirow[t]{3}{*}{$P$-value } \\
\hline & & Yes & No & & \\
\hline & & $\%$ & $\%$ & & \\
\hline \multicolumn{6}{|c|}{ Postpartum variables } \\
\hline Pacifier use during the first week of life & & & & $5.072(1)$ & 0.024 \\
\hline Yes & 73 & 34.2 & 57.8 & & \\
\hline No & 465 & 48.4 & 51.6 & & \\
\hline $\begin{array}{l}\text { Having enough time for exclusive } \\
\text { breastfeeding }\end{array}$ & & & & $10.89(1)$ & 0.001 \\
\hline Yes & 475 & 49.1 & 50.9 & & \\
\hline No & 63 & 27.0 & 73.0 & & \\
\hline Mother's breastfeeding history & & & & $2.040(1)$ & 0.090 \\
\hline Yes & 215 & 50.2 & 49.8 & & \\
\hline No & 323 & 44.0 & 56.0 & & \\
\hline
\end{tabular}

$d f=$ degrees offreedom .

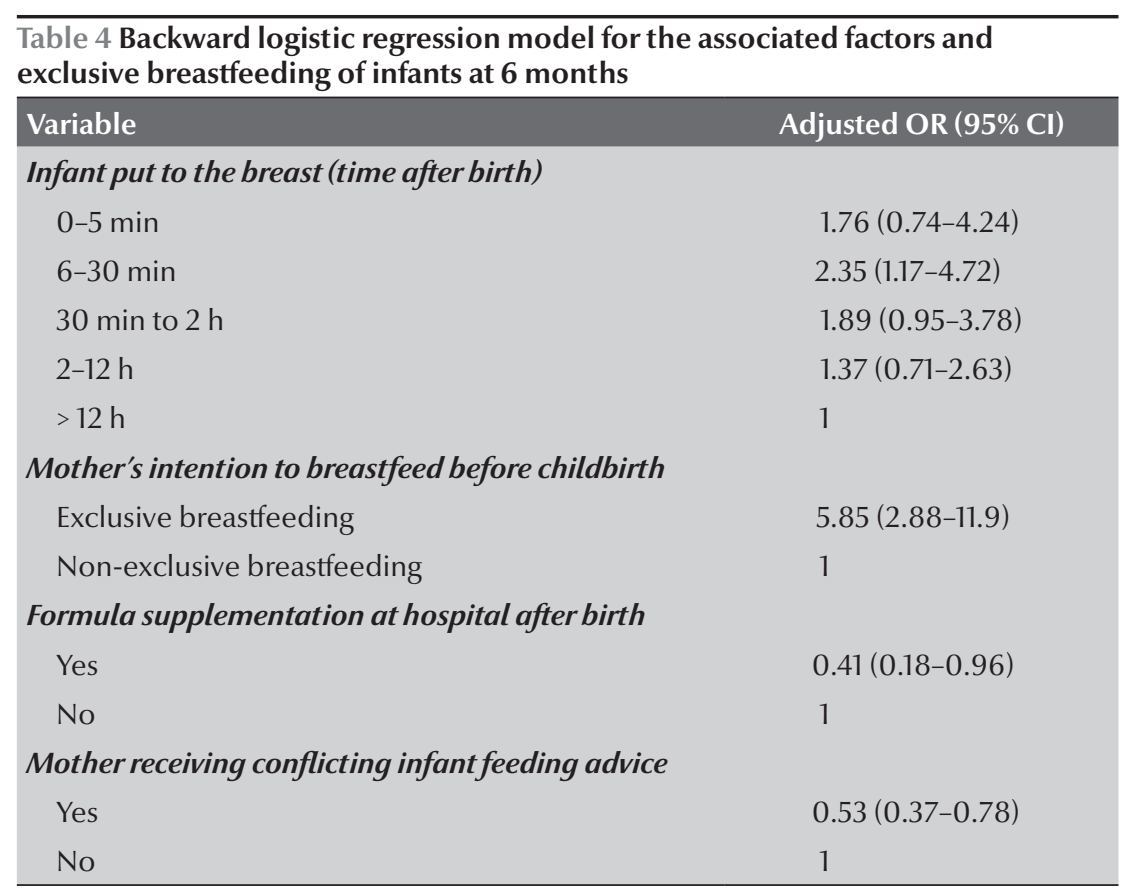

$O R=$ odds ratio; $C I=$ confidence interval.

intending to breastfeed before childbirth are more able to deal with any breastfeeding problems that may arise. The relationship between a mother's intention to breastfeed and exclusive breastfeeding supports the Theory of Reasoned Action. According to one behaviour [23]. In exclusive breastfeeding, only having information and a positive attitude are not sufficient, as the intention to breastfeed is also needed for success with exclusive breastfeeding [24].

The present study was cross-sectional and the relationship between associated factors and exclusive breastfeeding in the first 6 months of life were not causally related. Moreover, possible recall bias could be another limitation. Nevertheless, the results of this study regarding the prevalence of exclusive breastfeeding in the first 6 months of life and the associated factors may make a useful contribution to the development of efficient interventions for the promotion of breastfeeding.

\section{Acknowledgements} voluntary and a person's intention to do an action is a necessary factor for doing it and the intention to undertake special behaviour is influenced by that person's attitudes and thoughts and other people's attitudes towards that
Funding: This study was funded and supported by Tehran University of Medical Sciences; grant No. 89-04-2811899 as an MSc thesis.

Competing interests: None declared.

\section{References}

1. Kramer MS, Kakuma R. The optimal duration of exclusive breastfeeding: Cochrane Database of Systematic Reviews, 2007, 1:CD003517.
2. The optimal duration of exclusive breastfeeding: report of an expert consultation. Geneva, World Health Organization, 2001. 
3. American Academy of Pediatrics. Breastfeeding and the use of human milk. Pediatrics, 2005, 11:496-506.

4. Olang B et al. Breastfeeding in Iran: prevalence, duration and current recommendations. International Breastfeeding Journal, 2009, 4:8. doi:10.1186/1746-4358-4-8.

5. Vafaee A et al. Prevalence of exclusive breastfeeding during the first six month of life its determinant factors on the referring children to the health center in Mashhad, northeast of Iran-2007. Journal of Applied Sciences, 2010, 10:343-348.

6. Mohamadbeigi A, Salehi NM, Bayati A. [The pattern of exclusive breast feeding in referred neonatal to health centres of Arak]. Journal of Guilan University of Medical Sciences, 2010, 70:17-25 [in Farsi].

7. Almasi H, Saberi HR, Moravveji AR. [The pattern of exclusive breast feeding in neonates under healthcares in health centres of Kashan city during 2006]. Journal of Kashan University of Medical Sciences, 2010, 14:163-168 [in Farsi].

8. Eslami $Z$ et al. [The relationship between types of delivery on breastfeeding success]. Journal of Pediatrics of Iran, 2009, 18 1(winter special issue):47-52 [in Farsi].

9. Al-Sahab B et al. Prevalence and predictors of 6-month exclusive breastfeeding among Canadian women: a national survey. BMC Pediatrics, 2010, 10:20. doi:10.1186/1471-2431-10-20.

10. British national formulary 59. London, British Medical Association and the Royal Pharmaceutical Society, 2010.

11. Agho KE et al. Determinants of exclusive breastfeeding in Nigeria. BMC Pregnancy and Childbirth, 2011, 11:2. doi:10.1186/14712393-17-2.

12. Tan KL. Factors associated with exclusive breastfeeding among infants under six months of age in Peninsular Malaysia. International Breastfeeding Journal, 2011, 6:2. doi:10.1186/17464358-6-2.

13. Rowe-Murray HJ, Fisher JRW. Baby friendly hospital practices: cesarean section is a persistent barrier to early initiation of breastfeeding. Birth, 2002, 292:124-131.
14. Nakao $\mathrm{Y}$ et al. Initiation of breastfeeding within 120 minutes after birth is associated with breastfeeding at four month among Japanese women: A self-administered questionnaire survey. International Breastfeeding Journal, 2008, 3:1. doi:10.1186/1746-4358-3-1.

15. Global strategy for infant and young child feeding. Geneva, World Health Organization, 2003.

16. Fjeld $\mathrm{E}$ et al. No sister, the breast alone is not enough for my baby. International Breastfeeding Journal, 2008, 3:26. doi: 10.1186/1746-4358-3-26

17. Rose VA et al. Factor influencing infant feeding method in an urban community. Journal of the National Medical Association, 2004, 96:325-331.

18. Morhason-Bello I, O'Adedokun B, Ojengbede AO. Social support during childbirth as a catalyst for early breastfeeding initiation for first time Nigerian mothers. International Breastfeeding Journal, 2009, 4:16. 10.1186/1746-4358-16.

19. Dashti $M$ et al. Determinants of breastfeeding initiation among mothers in Kuwait. International Breastfeeding Journal, 2010, 5:7. doi:10.1186/1746-4358-5-7.

20. Semenic S, Loiselle C, Gottlieb L. Predictors of the duration of exclusive breastfeeding among first-time mothers. Research in Nursing and Health, 2008, 31:428-441.

21. Tarrant $\mathrm{M}$ et al. Breastfeeding and weaning practices among Hong Kong mothers: a prospective study. BMC Pregnancy and Childbirth, 2010, 10:27. doi:10.1186/1471-2393-10-27.

22. Scott JA et al. Factors associated with breastfeeding at discharge and duration of breastfeeding. Journal of Paediatrics and Child Health, 2001, 37:254-261.

23. Ajzen I, Albarracin D, Hornik R, eds. Prediction and change of health behavior: applying the reasoned action approach. Mahwah, New Jersey, Lawrence Erlbaum Associates, 2007.

24. Bai $Y$ et al. Predicting intentions to continue exclusive breastfeeding for 6 months: a comparison among racial/ethnic groups. Maternal and Child Health Journal, 2010, 15(8):1257-1264. 